This is an author produced version of a paper published in Population Ecology. This paper has been peer-reviewed and is proof-corrected, but does not include the journal pagination.

Citation for the published paper:

Ranius, T. (2006) Measuring the dispersal of saproxylic insects: a key characteristic for their conservation. Population Ecology.

Volume: 48 Number: 3, pp 177-188.

http://dx.doi.org/10.1007/s10144-006-0262-3

Access to the published version may require journal subscription.

Published with permission from: Springer Verlag

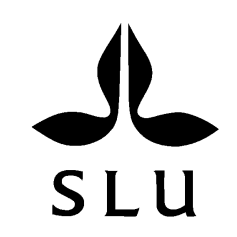

Epsilon Open Archive http://epsilon.slu.se 
DOI 10.1007/s10144-006-0262-3

Should be cited as:

Ranius, T. (2006). Measuring dispersal of saproxylic insects - a key characteristics for their conservation. Population Ecology 48: 177-188.

\section{Measuring dispersal of saproxylic insects - a key characteristic for their conservation}

Thomas Ranius

Dep. Entomology

Swedish University of Agricultural Sciences

P.O. Box 7044

SE - 75007 Uppsala

Sweden

E-mail address: thomas.ranius@entom.slu.se

Telephone: ++46-18-672334

FAX: ++46-18-672890 
Abstract. In nature conservation it is important to understand under which circumstances populations can survive by compensating local extinctions with colonisations. Many saproxylic (= wood-dwelling) insect species have declining populations and are regarded as threatened due to low habitat availability in managed forests. Several methods have been used to better understand the dispersal biology and colonisation ability of saproxylic insects with declining populations. In this paper, I summarize and compare the results of such studies. When the same species have been studied using several methods, the results are consistent, but different aspects of dispersal biology are revealed with different methods. Capturerecapture and telemetry are direct methods that can be used to quantify dispersal rate and range in the field. Studies of genetic structure and occupancy patterns are complementary, as they reveal the consequences of dispersals that have taken place over a larger spatial and temporal scale than is possible to study with direct methods. Because colonisation, rather than dispersal, is most important for population persistence, colonisation experiments provide useful information. To obtain information relevant for conservation work dispersal studies should be conducted on model species that are representative of threatened species. Colonisation ability probability differs between common and rare species, and therefore it is important to also study dispersal of rare species, even if it is more difficult.

Key terms: capture-recapture, colonisation, dead wood, Osmoderma eremita, telemetry, tethered flight 


\section{Introduction}

In order to understand population dynamics and assess extinction risks, knowledge about species’ dispersal rate and range are important. Dispersal is necessary for gene flow (e.g. Slatkin 1987), colonisation of empty habitat (e.g. Hanski et al. 1994), and may also affect the population dynamics (Pulliam 1988) and extinction risks of local populations (Brown and Kodrick-Brown 1977). Therefore, dispersal affects how the populations are able to cope with changes in the environment, such us habitat loss and fragmentation (Thomas 2000). Models that do not explicitly involve costs for dispersal (such as Levins' $(1969,1970)$ metapopulation model) suggest that dispersal is always beneficial. If the dispersal rate is high, however, an increased local extinction risk may make species with high dispersal rates more vulnerable in fragmented landscapes (Hanski and Zhang 1993). Empirical data support the view that there is no simple positive relationship between dispersal and population persistence in fragmented landscapes; Thomas (2000) related the recent decline of British butterfly species with their proneness for dispersal and found that species in the intermediate category had experienced the most serious declines, while both more mobile and more sedentary species had persisted better. This pattern is dependent on the degree of fragmentation; at a later stage in the fragmentation process, we should expect the sedentary species to be the most affected, while the most mobile species to a high extent would still persist (Thomas 2000). The strategy for nature conservation should take into consideration the colonisation ability of target species. For those species with a limited colonisation ability it is important to identify the localities where they exist, and maintain and improve the habitat quality within, or nearby, those localities (Huxel and Hastings 1999). For conservation of species with a high capacity for colonisation of habitat patches far away other criteria should be used for cost-efficient conservation efforts. For instance, localities where it is possible to improve the habitat quality most quickly could be selected (Ranius and Kindvall 2006). 
A large proportion of forest insects are saproxylic, i.e. dependent on dead wood directly, or dependent on other saproxylic organisms (Speight 1989). Because there is little dead wood in intensively managed forests, many saproxylic insects have decreased and are regarded as threatened (Siitonen 2001). This paper reviews the literature on the dispersal of saproxylic insects, with a focus on species that may be targets for conservation efforts. The aim is to compare which conclusions that are possible to draw dependent on which method that is used. I also present some new analyses on already published data that I and colleagues have collected on beetles inhabiting tree hollows, especially Osmoderma eremita.

\section{Capture-recapture}

The capture-recapture technique is useful when assessing population sizes, but does also yield direct observations of marked individual's movements. Information about dispersal have also been obtained by recapture of individuals released from certain dispersal sources (e.g. Togashi 1990). Models have been developed to estimate migration parameters from capturerecapture studies (Hanski et al. 2000, Ovaskainen 2004). When dispersal rate and range of saproxylic insects have been studied, these models have not been applied. This is because saproxylic insects have not been captured in every habitat patch in entire landscapes, and at least in some case, the number of observed migrations have been too small.

Capture-recapture has been used in metapopulation studies of the beetle species Osmoderma eremita (Ranius and Hedin, 2001), Bolitotherus cornutus (Whitlock 1992, Starzomski and Bondrup-Nielsen 2002), and Bolitophagus reticulatus (Nilsson 1997). Larvae of Osmoderma eremita develop in hollow trees, and there also the adults are mainly found (Fig. 1). The adults survive for a month and do usually not feed. Larvae of B. reticulatus and B. cornutus develops in sporocarps of a bracket fungus that frequently occur in dead wood (Fig. 2). The adults also feed on the sporocarps, and their life-time may be up to three years. 
Hollow oaks are a more long-lived habitat in comparison to sporocarps, and therefore we expect species in hollow oaks to be generally more sedentary than those in sporocarps. This is because theoretical analyses as well as some empirical studies suggest species in long-lived habitats to have more limited dispersal in comparison to those in short lived habitats (e.g. Southwood 1962, Johnson and Gaines 1990, Roff 1994). Among the 377 O. eremita individuals that were captured at least twice by Ranius \& Hedin (2001), 2.4\% were observed to move from one tree to another. In Whitlock's (1992) study of B. cornutus, movements between logs were observed for $14.6 \%$ of the 288 adult beetles captured at least twice. For $B$. reticulatus, 932 individuals were captured at least twice, and among them movements between logs were observed for 30.3\% of the individuals (Nilsson 1997). These figures are underestimates of the dispersal rate, because many individuals disperse to trees or logs not included in the study, or they disperse before the first time they were captured or after the last time they were recaptured. In the $O$. eremita study, this was adjusted using a computer simulation model, which suggested that $15 \%$ of the $O$. eremita individuals moved to other trees during their entire life-time (Ranius and Hedin 2001). Whitlock (1992) estimated the dispersal rate to be $31 \%$, taking into account immigration from the surroundings and the time period between captures in relation to the adult beetles' life-time. No similar analysis was conducted for B. reticulatus, but it is likely that for this species the actual dispersal rate is also considerably higher than the observed proportion (30.3\%).

In a metapopulation in equilibrium, the local extinction rate is equal to the colonisation rate. Osmoderma eremita was studied over five years, and that was obviously too short a period for being observing colonisations and local extinctions. For B. cornutus, the disappearance rate was 0.10 per log and year (equal to the disappearance rate of habitat patches), which means that the mean longevity of a local population is 9 years (Whitlock 1992). For B. reticulatus, Nilsson (1997) reported that the species disappeared from logs at a 
rate of 38\% per year, and thus the mean longevity would be 2 years. Given that for $B$. reticulatus, the larval development takes one year and the adult beetles survive 1-3 years, the average longevity in a log is of the same magnitude as the life-time of an individual.

Based on the dispersal rate, $O$. eremita has been described as a metapopulation (Ranius and Hedin 2001), with each tree regarded as a habitat patch that potentially hosts local populations. These local populations are partly independent, and therefore there is an asynchrony in the population fluctuations (Ranius 2001). In contrast, for B. cornutus Starzomski and Bondrup-Nielsen (2002) concluded that a local population potentially covers an area encompassing a group of logs rather than an individual log with sporocarps. Regarding $B$. reticulatus, it is even more obvious that the dispersal between logs is so extensive, and the individuals arrive and disappear so often, that it makes no sense to describe the individuals found in an individual log as a local population. Despite this, Nilsson's study has been used as an argument for a metapopulation structure of $B$. reticulatus with individual logs harbouring local populations (Nilsson 1997, Rukke and Midtgaard 1998).

The dispersal rate of $O$. eremita has also been studied with telemetry, and with this method dispersal rates similar to those using mark-recapture were obtained (Hedin et al. 2003). The dispersal rates of $B$. cornutus and $B$. reticulatus have not been estimated with any other method. However, the dispersal rate and colonisation-extinction-dynamics affects the genetic structure, which for these species has been found to be consistent with an extensive turn-over rate of populations in individual logs (B. cornutus: Whitlock 1992; B. reticulatus: Jonsson et al. 2003).

It is difficult to assess dispersal ranges from capture-recapture studies (Schneider 2003). Nilsson's (1997) study was conducted in an area less than 1 ha, and thus it is obviously impossible to draw conclusions about dispersal longer than a few tens of metres, which explains why no dispersal ranges were presented. Whitlock’s (1992) study was carried out in 
a $50 \mathrm{~m} \times 600 \mathrm{~m}$ area, and there the mean observed movement distance was $27 \mathrm{~m}$. O. eremita was studied in two areas (400 x 500 m, and $1500 \times 2000$ m, respectively). The observed dispersals were within a range of 30-190 m. In a telemetric study carried out in the same study area, dispersals of 10-180 m were observed.

The dispersal distance distribution of $O$. eremita obtained by capture-recapture and telemetry was compared with the prediction from a power function $\left(\mathrm{P}=\mathrm{a} \mathrm{D}^{-\mathrm{n}}\right)$ and a negative exponential function $(\mathrm{P}=\exp (-\mathrm{D} / \mathrm{k}))$, where $P$ is the probability that an individual moves the distance $D$ or longer, and $a, n$ and $k$ are constants. The negative exponential function has been used in metapopulation models (Hanski et al. 2000), but there are several empirical studies where the power function has been found to fit better with field data (e.g. Hill et al. 1996, Baguette et al. 2000, Roslin 2000). However, in O. eremita the negative exponential curve fitted best with field data (Fig. 3, for logarithmic values: Pearson correlation coefficient (negative exponential function) $=0.97$; Pearson correlation coefficient $($ power function $)=$ 0.88). The value of $k$ is equal to the mean dispersal distance, and was found to be $60 \mathrm{~m}$. For distances $>200 \mathrm{~m}$, the negative exponential function predicts that less than one movement would be observed in the two studies totally. Thus, there is no reason to believe that the distance of the longest observed dispersal (190 m) represents any maximum limit for dispersal; dispersal over longer distances is predicted to be so rare that they could easily remain unobserved in field studies. Because no physiological limit in the dispersal range of $O$. eremita is known, we should leave the negative exponential function untruncated. This means that the dispersal range might be infinite, however, the probability for such a range tends towards zero. An example of a prediction that can be made by the function is that $1.6 \%$ of the dispersing individuals move $>250 \mathrm{~m}$. Given that the number of adult beetles emerging each year in an area with a high density of suitable trees (Bjärka-Säby, Sweden) has been estimated to be 1,300 (Ranius 2001), and the dispersal rate is estimated to be $15 \%$, it can be expected 
that each year about 3 adult beetles move more than $250 \mathrm{~m}$. If the same function is used in small stands of hollow trees inhabited by $O$. eremita (with some tens of beetles emerging every year, Ranius 2000), there would be about one beetle moving more than 250 m every ten years. It is likely that the probability of such dispersal events varies between years and is dependent on weather (e.g. Kindvall 1995, Nève et al. 1996), however, it has so far not been possible to show any such relationship for O. eremita (Ranius and Hedin 2001)

Because the $O$. eremita beetles move from one suitable tree to another (Hedin et al. 2003), their dispersal range is not only an effect of the species biology, but at least to some extent it is also affected by the spatial structure of the trees. The dispersal range has so far only been studied at two localities where the density of suitable trees is high. Consequently, it is not known how the dispersal rate and range will differ in a landscape with a lower density of hollow trees (cf. Mennechez et al. 2003). However, in a landscape with many small stands of hollow oaks, single suitable trees remained uncolonised if they are situated only a few hundred metres from stands where the species is present (Ranius 2000). Thus, it does not seem that the dispersal range would be much larger when the stands of hollow trees are small.

\section{Telemetry}

Besides mark-recapture techniques, telemetry is the only method to obtain direct measures of field dispersal. Telemetry is possible to use on larger insects, also to follow flying individuals. It has been used on the saproxylic beetles Lucanus cervus (Sprecher-Uebersax and Durrer 2001) and Osmoderma eremita (Fig. 4, Hedin and Ranius 2002, Hedin et al. 2003), and on the beetle Scapanes scapanes that bores in wood of living coconut palms (Beaudoin-Ollivier et al. 2003). The weight of the radio transmitters used have been $0.4-0.52 \mathrm{~g}$. That corresponded with 12-20 \% of beetles’ weight for Lucanus cervus, 20-25 \% for O. eremita, and 5-7\% for Scapanes scapanes. 
A great advantage with telemetry is that it is possible to also observe those movements that end in unexpected habitats, while with capture-recapture, it is only possible to recapture individuals that move to habitats where the species is searched for. A disadvantage is that the radio transmitters may affect the behaviour of the individuals. When the method has been used, however, there have been no obvious signs of changed behaviour, even for the smallest species (Hedin and Ranius 2002). In the study on O. eremita the beetles were tracked every day, and if a beetle had disappeared from the location where it was found at the last observation, it was searched for within a radius of $800 \mathrm{~m}$ from that point. Thus, movements exceeding $800 \mathrm{~m}$ were not possible to observe, however, given the results presented in Fig. 3, such movements were probably very rare, if they existed at all. For several $O$. eremita beetles tagged with radio transmitters, contact was lost before the batteries were expected to be discharged. This was at least in some cases because the transmitters were damaged as a consequence of moisture seeping into them (Hedin and Ranius 2002). However, for several individuals it was impossible to rule out the possibility that they had moved too far away to be tracked.

Among 26 transmitter-tagged females, three were observed to disperse (12\%), while the corresponding value for 39 males was five (13\%) (Hedin et al. 2003). Thus, no difference in dispersal rate were observed between males and females. Better data were yielded for males in comparison to females, because for more females contact was lost. 82-88 \% of the adults remained in their natal trees. All observed movements ended up in hollow oaks regarded as suitable for the species, situated less than $200 \mathrm{~m}$ from the natal tree. Only for one male, more than one dispersal $(160 \mathrm{~m}+20 \mathrm{~m})$ between trees were observed.

Sprecher-Uebersax and Durrer (2001) studied four females and four males of Lucanus cervus. For every individual they observed several movements. On the contrary to $O$. eremita, 
there was a clear difference between sexes: males flow longer distances (often about $200 \mathrm{~m}$ per flight), while females only dispersed shorter distances by walking.

\section{Occurrence patterns}

A species' occurrence patterns observed in a landscape may be the result of colonisations and extinctions in individual habitat patches (e.g. Peltonen and Hanski 1991, Thomas et al. 1992). Therefore, such patterns could be used as an indirect measure of colonisation rates. The present occurrence patterns, however, are not only dependent on the current habitat amount and structure but may also reflect the situation historically (Hanski and Ovaskainen 2002). Research related to nature conservation is often focused on species inhabiting declining habitats. Therefore, the habitat density has in many cases been historically higher than at present. Because the occurrence pattern results both from the colonisation rate and the extinction risk, and is affected both by present and historical characteristics of the landscape (and the latter are more or less unknown) it is often difficult to draw firm conclusions about dispersal from occurrence patterns alone. However, because direct studies of dispersal are usually conducted on a limited area over only a few years, studies of occurrence patterns could constitute a valuable complement, as they reflect the long-term effects of the colonisation ability and could be conducted over a larger area.

The relationship between species occupancy and habitat density is dependent on the spatial scale. Thus, several different spatial scales should be considered (as in Rukke and Midtgaard 1998, Kehler and Bondrup-Nielsen 1999). A method has been developed that can be used when comparing the strength of the relationship at different spatial scales (Holland et al. 2004). Usually, the spatial scale of the colonisations is interpreted from the relationship between occupancy and habitat patch connectivity or isolation. As a measure of isolation, it has been common to use the distance to a limited number of neighbouring habitat patches that 
are the closest to each habitat patch (Rukke and Midtagaard 1998, Nilsson 1997, SverdrupThygeson and Midtgaard 1998, Kehler and Bondrup-Nielsen 1999). With this measure information is lost because it assumes implicitly that only a very limited number of habitat patches may be relevant as dispersal sources, while all other habitat patches are irrelevant. Ranius (2000) used the number of hollow trees per stand as a measure of connectivity. This was possible because the hollow trees were clustered into stands, but also in that study the hollow trees were either regarded as relevant (within the stand) or irrelevant (belonging to another stand) as dispersal sources. In many cases it may be more appropriate to use a connectivity measure developed by Hanski (1999), that takes into account all habitat patches that could possibly act as dispersal sources, and weight these patches in relation to the distance and the expected mean dispersal distance of the study species.

Ranius (2000) found that the occupancy of $O$. eremita per tree was positively correlated with stand size (Fig. 5), but the occupancy per stand was not related to the number and size of surrounding stands. Combined with data from capture-recapture (Ranius \& Hedin 2001), this suggests that dispersal within stands affects the current occupancy pattern, while dispersal between stands is so rare that it does not influence the species' occupancy. Instead, at the larger scale the occurrence pattern mainly reflects the extinction risk in the stands. Also for some other species belonging to the same community, the beetles Elater ferrugineus and Tenebrio opacus (Ranius 2002a), and the pseudoscorpion Larca lata (Ranius and Wilander 2000), a positive relationship between occupancy per tree and stand size was found (Fig. 5). Because there are no studies on the dispersal or population dynamics of these species, it was more difficult to determine whether this relationship was a result of their limited dispersal between stands or of higher extinction risk per stand, in relation to those species for which this pattern was not found (Ranius 2002a). However, an analysis presented below (Table 1) 
lends some support to the view that Elater ferrugineus and Tenebrio opacus have a lower dispersal rate than many other beetle species associated with tree hollows.

In a study of Bolitotherus cornutus, a negative relationship between occupancy and isolation was found at all three spatial scales of study (Kehler and Bondrup-Nielsen 1999). Kehler and Bondrup-Nielsen (1999) suggest that the small-scale pattern may arise from dispersal patterns by walking, while the large-scale pattern arises from dispersal patterns by flying.

Also for Bolitophagus reticulatus, a negative relationship between occupancy and isolation has been observed at a per log scale (Rukke and Midtgaard 1998, SverdrupThygeson and Midtgaard 1998). As previously suggested for $B$. cornutus, also this might be a result of dispersal by walking between closely situated logs (Jonsell et al. 2003). However, when the effect of isolation was studied at a larger scale, there was no significant relationship (Rukke and Midtgaard 1998). This might be because the beetles tend to fly so frequently and over such long distances (Jonsson 2003) that in the landscape studied by Rukke and Midtgaard (1999), the occupancy per forest island was not restricted by limited colonisation.

Thus, both for B. reticulatus (Rukke and Midtgaard 1999) and O. eremita (Ranius 2000) there was no relationship between occurrence per stand and stand isolation, but different conclusions are drawn. This is because for $O$. eremita, the occupancy per tree was systematically lower in smaller stands (and thus, the species was absent in many of the smallest stands), which not would be the case if the beetles readily moved between trees belonging to different stands. For $B$. reticulatus this was not analysed by Rukke and Midtgaard (1999), however, in a study by Jonsell et al. (2003) there was no relationship between the species’ occupancy per sporocarp and habitat density per forest.

\section{Genetic studies}


Similar to studies of occurrence patterns, genetic studies are useful when assessing the longterm effect of dispersal, also at a larger spatial scale. A few genetic studies are concerned with dispersal of saproxylic invertebrate species that have been studied also in other aspects. Jonsson et al. (2003) compared the genetic structure of a common (B. reticulatus) and a rare beetle (O. haemorrhoidalis) beetle living in sporocarps of a bracket fungi. Between sites, the genetic differentiation was larger in $O$. haemorrhoidalis. It seems that gene flow between $O$. haemorrhoidalis populations has declined as an effect of recent fragmentation, while $B$. reticulatus likely moves over large areas and has higher gene flow (Jonsson et al. 2003). Knutsen et al. (2000) also studied B. reticulatus. In accordance with Jonsson et al. (2003) they found only a very small genetic differentiation at a larger geographical scale, between their two study areas. They found significant genetic differentiation between trees, probably due to a founder effect (Jonsson et al. 2003). Also for Bolitotherus cornutus, an increased genetic variance between different logs was found to be an effect of the extinction-colonisation process at the log level (Whitlock 1992). Ranius and Douwes (2002) studied the genetic structure of two pseudoscorpion species. These species could obviously not fly between localities, and phoretic dispersal has only occasionally been observed. Despite that, the genetic differentiation was low for the species, both between trees and between sites situated 4-900 km from each other.

The genetic studies on saproxylic organisms have provided hints about the dispersal rate, however, there are often several possible explanations for the observed patterns. It is mainly because the observed genetic differentiation not only reflects the current dispersal rate, but is also affected by, for instance, bottlenecks in the local populations, extinctioncolonisation events, and historic dispersal rates (Slatkin 1987, Bossart and Pashley Prowell 1998). Another problem with genetic studies is that when rare saproxylic invertebrates are studied, it is often difficult (or at least ethically questionable) to have a large enough sample 
size. So far, allozymes and RAPD have been used, which has limited the number of genetic markers. It is expected that modern molecular techniques (e.g. AFLP genotyping: Mueller and Wolfenbarger 1999) will improve the possibilities to obtain enough sample size even if a smaller number of individuals is used.

\section{Tethered flight}

In the lab, it is possible to assess the tethered flight of insects in flight-mills (Fig. 6). This method has been used to study the flight capacity and propensity especially for pest species. Forsse (1991) used tethered flight to study how migratory behaviour varies among geographic populations of Ips typographus. Jonsson (2003) has used tethered flight to compare the flight distance of one rare (Oplocaphala haemorrhoidalis) and one common (Bolitophagus reticulatus) beetle species inhabiting sporocarps of a bracket fungi. He found that both species were able to fly for very long time periods, which can be assumed to be translated into long distances. B. reticulatus carried out more but shorter flights in comparison to $O$. haemorrhoidalis (Fig. 7).

Because it is not known how much of the flight potential expressed in the laboratory that actually is used under field conditions (Forsse and Solbreck 1985), the absolute measures from tethered flight studies might be less useful, however, this method is obviously useful for comparisons of the dispersal biology between populations and species. Moreover, it can be used to understand whether a dispersal range function should be truncated because of physiological limits, or if the maximum possible dispersal range is so large that the function should have no truncation (as supposed in Fig. 3). Tethered flight could give information about differences in dispersal biology between sexes, and between periods of an individual's life-time (Humphry and Linit 1989), which might be useful for interpretations of dispersal data obtained by other methods. 


\section{Observations of flying individuals}

Sometimes, occasional observations of flying insects (or absence of them) have been used to approximate dispersal behaviour (e.g. Nilsson and Baranowski 1994). The willingness to fly could be studied in a more systematic way in experiments in which attempts to take off are registered (Jonsson 2003). Another method to estimate insect flight is to use window traps, which sample flying individuals. However, many other behavioural differences between the species will obviously also influence this estimate. Here I summarize data from a study where the results from window traps and pitfall traps set in the same trees were compared (Ranius and Jansson 2002, Fig. 8). The pitfall traps were set in tree hollows, and consequently only species associated with that microhabitat were considered (according to Ranius and Jansson's (2002) classification). By comparing the number of individuals captured by window traps with the number of individuals captured in the same trees by pitfall traps, an estimate was obtained that is related to the species' proneness to fly. The outcome was compared with the relationship between occupancy per tree and stand size observed in another independent survey (Table 1). The strong correlation between the results (Table 1) from these two independent studies supports the view that a low tendency to be captured in window traps did indeed reflect a low dispersal proneness.

\section{Colonisation experiments}

For metapopulation survival, it is the colonisation rate that is relevant rather than dispersal. A restricted capacity to colonise suitable habitat patches may be because a small population size, low dispersal rate, low dispersal range, high dispersal mortality, or a low ability to establish a new population (e.g. due to a limited fecundity or ability to compete with other species). 
Colonisation has been studied directly by experimentally arranging empty habitat patches. Whitlock (1992), Jonsell et al. (1999) and Jonsson and Nordlander (2006) used sporocarps of bracket fungi that were collected alive and frozen to kill the insects (Fig. 9). Whitlock (1992) assessed the colonisation rate of Bolitotherus cornutus. Jonsell et al. (1999) compared the colonisation patterns between species. For instance, they found that Dorcatoma spp. were better colonisers than Cis spp., and that parasitoids appeared more affected by distance than their hosts. The colonisation rate is a function of the size of the dispersal source, however, no amount of habitat or estimated population sizes were presented. Thus, it is not possible to draw any general conclusions about the colonisation rate in different circumstances from these experiments. Jonsson and Nordlander (2006) studied the steepness in the decline in colonisation rate with distance from an old-growth forest. One of their main results was that for Cis quadridens, a colonisation frequency clearly decreasing with distance was obtained, while for $C$. glabratus there was no such trend at all (Fig. 10). This difference in colonisation ability may explain why $C$. glabratus occurs even in managed forests with a low habitat density, while C. quadridens rarely does (Jonsell and Nordlander 2002). A study in a much larger spatial scale was conducted by Nilssen (1984), who placed recently cut logs of Norway spruce at different distance from the nearest spruce forest. He found that some bark beetles colonised also those logs situated $171 \mathrm{~km}$ north from the northern limit for spruce forests.

\section{To interpret dispersal data: combining methods and extrapolating between species and} spatial scales

No method gives a complete picture of a species’ dispersal biology. Consequently, a combination of several different methods to study dispersal is often useful. One example of methods that have been fruitful to combine is the telemetric and capture-recapture study on $O$. 
eremita. In the interpretation of telemetry data, the adult life-time obtained from the capturerecapture study was essential (Hedin et al. 2003), while for the interpretation of the capturerecapture study, information about the end-point of dispersals obtained in the telemetry study was required (Ranius and Hedin 2001). Also combinations of direct and indirect methods are fruitful, as they reveal different aspects of the dispersal biology.

Independent of the method used, the spatial scale of the study may affect the outcome. For instance, in capture-recapture studies, movements over longer distances than the study area will obviously never be detected, and instead the migrating individuals just 'disappear' (Koenig et al. 1986). Another example is from the genetic studies of B. reticulatus, where Knutsen et al. (2002) found the dispersal to be limited, while Jonsson et al. (2003) concluded that the dispersal was relatively more extensive. To some extent this difference was because Knutsen et al. (2002) studied the genetic differentiation only at a smaller scale, while Jonsson et al. (2003) also included larger scales in their study. Usually it is much easier to obtain data from a smaller spatial scale. However, the rare long-distance dispersals are the most important for species persistence at a landscape level. Therefore it might be tempting to extrapolate the results from a small to a larger scale. One example is the conclusion by Jonsell et al. (1999) that "it is reasonable to assume that most of the insects included in this study can colonize substrate within $1 \mathrm{~km}$ of their point of origin, and the Dorcatoma species should be able to cover even longer distances”, even though they had only studied colonisations 0-500 m from the potential dispersal sources. Another example is given in this paper: I estimate the expected number of Osmoderma eremita dispersing more than $250 \mathrm{~m}$, even though no such dispersal has been observed (however, the study design allowed such observations). This may be acceptable since information about dispersal of threatened organisms is needed for nature conservation urgently. Therefore, it is better to use preliminary information on dispersal from extrapolations than to use guesses that have no scientific basis at all. However, it is important 
to point out which information is supported by data from empirical studies and what reasoning lies behind any extrapolation from such data.

It is impossible to study the dispersal biology of all species, because dispersal studies are very time-consuming. Furthermore, it is easier to study the dispersal of some species than others, for instance because there are efficient methods to capture them or to systematically survey them in a landscape, or there are more markers that can be used in genetic studies. Therefore, dispersal is studied in some model species, and it is assumed that they are good representatives for whole assemblages of species. This approach involves an extrapolation from a few model species to other species presumed to be similar.

Extrapolations to other spatial scales and to other species may generate pitfalls that should be avoided. First, because it is often difficult to observe dispersal, early studies tend to suggest low dispersal, while when an appropriate method and an appropriate spatial scale has been used, more dispersal is observed (Schneider 2003). This development has taken place for many butterfly species (Hanski 1999). The second pitfall arises when inappropriate model species are used. Generally, it is easier to study common species instead of rare ones. However, we should expect non-threatened species, on average, to be stronger colonisers than threatened species (Kotiaho et al. 2005). Consequently, if studies of non-threatened species are used to understand the dispersal biology of threatened species that have been difficult to study, there is a risk that dispersal would be overestimated. The conclusion "insects are generally characterized by high motility” (e.g. Hansson et al. 1993, in a textbook on nature conservation) is logical, if based on those many dispersal studies that have been conducted on pest species and other model species that have been easy to study. However, it could obviously be deleterious for nature conservation if it is used as a general rule-of-thumb also for threatened species with an unknown dispersal biology. 


\section{Acknowledgements}

Barbara Ekbom, Markus Franzén, Mats Jonsell, Stig Larsson and Martin Schroeder have given valuable comments to the manuscript. This work has been done within the project "Predicting extinction risks for threatened wood-living insects in dynamic landscapes" financed by The Swedish Research Council for Environment, Agricultural Sciences and Spatial Planning. We were kindly permitted to reprint figures from Computers and Electronics in Agriculture (copyright by Elsevier), Entomologisk Tidskrift and Animal Biodiversity \& Conservation.

\section{References}

Baguette M, Petit S, Quéva F (2000) Population spatial structure and migration of three butterfly species within the same habitat network: consequences for conservation. $\mathrm{J}$ Appl Ecol 37:100-108

Beaudoin-Ollivier L, Bonaccorso F, Aloysius M, Kasiki M (2003) Flight movement of Scapanes australis australis (Boisduval) (Coleoptera: Scarabaeidae: Dynastinae) in Papua New Guinea: a radiotelemetry study. Austral J Entomol 42:367-372

Bossart JL, Pashley Prowell D (1998) Genetic estimates of population structure and gene flow: limitations, lessons and new directions. Trends Ecol Evol 13:202-206

Brown JH, Kodrick-Brown A (1977) Turnover rates in insular biogeography: effect of immigration on extinction. Ecology 58:445-449

Forsse E (1991) Flight propensity and diapause incidence in five populations of the bark beetle Ips typographus in Scandinavia. Entomol Exp et Appl 61:53-57

Forsse E, Solbreck C (1985) Migration in the bark beetle Ips typographus L.: duration, timing and height of flights. Zeitschrift für angewandte Entomologie 100:47-57

Hanski I (1999) Metapopulation ecology. Oxford University Press, New York 
Hanski I, Ovaskainen O (2002) Extinction debt at extinction threshold. Conserv Biol 16:666-673

Hanski I, Zhang D-Y (1993) Migration, metapopulation dynamics and fugitive co-existence. J Theor Biol 163:491-504

Hanski I, Kuussaari M, Nieminen M (1994) Metapopulation structure and migration in the butterfly Melitaea cinxia. Ecology 75:747-762

Hanski I, Alho J, Moilanen A (2000) Estimating the parameters of survival and migration of individuals in metapopulations. Ecology 81:239-251

Hansson L, Söderström L, Solbreck C (1992) The ecology of dispersal in relation to conservation. In: Hansson, L (Ed) Ecological principles of nature conservation: applications in temperate and boreal environments. Elsevier Applied Science, London, pp 162-200

Hedin J, Ranius T (2002) Using radio telemetry to study dispersal of the beetle Osmoderma eremita, an inhabitant of tree hollows. Comput Electron Agr 35:171-180

Hedin J, Ranius T, Nilsson SG, Smith HG (2003) Predicted restricted dispersal in a flying beetle confirmed by telemetry. In: J Hedin. Metapopulation ecology of Osmoderma eremita - dispersal, habitat quality and habitat history. Dissertation. Lund University, Lund, pp 75-81

Hill JK, Thomas CD, Lewis OT (1996) Effects of habitat patch size and isolation on dispersal by Hesperia comma butterflies: implications for metapopulation structure. J Anim Ecol $65: 725-735$

Holland JD, Bert DG, Fahrig L (2004) Determining the spatial scale of species' response to habitat. Bioscience 54:229-235

Humphry SJ, Linit MJ (1989) Tethered flight of Monochamus carolinensis (Coleoptera: Cerambycidae) with respect to beetle age and sex. Environ Entomol 18:124-126 
Huxel GR, Hastings A (1999) Habitat loss, fragmentation, and restoration. Restoration Ecology 7:309-315

Johnson ML, Gaines MS (1990) Evolution of dispersal: theoretical models and empirical tests using birds and mammals. Annu Rev Ecol Syst 21:449-480

Jonsell M, Nordlander G (2002) Insects in polypore fungi as indicator species: a comparison between forest sites differing in amounts and continuity of dead wood. For Ecol Manage $157: 101-118$

Jonsell M, Schroeder M, Larsson T (2003) The saproxylic beetle Bolitophagus reticulatus: its frequency in managed forests, attraction to volatiles and flight period. Ecography $26: 421-428$

Jonsell M, Nordlander G, Jonsson M (1999) Colonization patterns of insects breeding in wood-decaying fungi. J Insect Conserv 3:145-161

Jonsson M (2003) Colonisation ability of the threatened tenebrionid beetle Oplocephala haemorrhoidalis and its common relative Bolitophagus reticulatus. Ecol Entomol 28:159-167

Jonsson M (2005) Spridningsförmågan hos insekter knutna till klibticka och fnöskticka [Dispersal abilities of insects associated with fruiting bodies of the wood-decaying fungi Fomitopsis pinicola and Fomes fomentarius. In Swedish, Engl. abstr.]. Ent Tidskr 126:205-213

Jonsson M, Johannesen J, Seitz A (2003) Comparative genetic structure of the threatened tenebrionid beetle Oplocephala haemorrhoidalis and its common relative Bolitophagus reticulatus. J Insect Conserv 7:111-124

Jonsson M, Nordlander G (2006) Insect colonisation of fruiting bodies of the wood-decaying fungus Fomitopsis pinicola at different distances from an old-growth forest. Biodiv Conserv, in press 
Kehler D, Bondrup-Nielsen, S (1999) Effects of isolation on the occurrence of a fungivorous forest beetle, Bolitotherus cornutus, at different spatial scales in fragmented and continuous forests. Oikos 84:35-43

Kindvall O (1995) The impact of extreme weather on habitat preference and survival in a metapopulation of the bush cricket Metrioptera bicolor in Sweden. Biol Conserv 73:51-58

Knutsen H, Rukke BA, Jorde P-E, Ims RA (2000) Genetic differentiation among populations of the beetle Bolitophagus reticulatus (Coleoptera: Tenebrionidae) in a fragmented and continuous landscape. Heredity 84:667-676

Koenig WD, Van Vuren D, Hooge PN (1996) Detectability, philopatry, and the distribution of dispersal distances in vertebrates. Trends Ecol Evol 11:514-517

Kotiaho JS, Kaitala V, Komonen A, Päivinen J (2005) Predicting the risk of extinction from shared ecological characteristics. P Natl Acad Sci USA 102:1963-1967

Levins R (1969) Some demographic and genetic consequences of environmental heterogeneity for biological control. Bull Ent Soc Am 15:237-240

Levins R (1970) Extinction. In: Gerstenhaber, M. (ed.) Some Mathematical Problems in Biology. American Mathematical Society, Providence, RI., pp 75-107

Mennechez G, Schtickzelle N, Baguette M (2003) Metapopulation dynamics of the bog fritillary butterfly: comparison of demographic parameters and dispersal between a continuous and a highly fragmented landscape. Land Ecol 18:279-291

Mueller UG, Wolfenbarger L (1999) AFLP genotyping and fingerprinting. Trends Ecol Evol $14: 389-394$

Nève G, Barascaue b, Hughes R, Aubert J, Descimon H, Lebrun P, Baguette M (1996) Dispersal, colonization power and metapopulation structure in the vulnerable butterfly Proclossiana eunomia (Lepidoptera: Nymphalidae) J Appl Ecol 33:14-22 
Nilssen AC (1984) Long-range aerial dispersal of bark beetles and bark weevils (Coleoptera, Scolytidae and Curculionidae) in northern Finland. Ann Entomol Fenn 50:37-42 Nilsson T (1997) Metapopulation dynamics in the black tinder fungus beetle, Bolitophagus reticulatus. In: Spatial population dynamics of the black tinder fungus beetle, Bolitophagus reticulatus (Coleoptera: Tenebrionidae). Dissertation. Uppsala University, Uppsala

Nilsson SG, Baranowski R (1994) Indikatorer på jätteträdskontinuitet - svenska förekomster av knäppare som är beroende av grova, levande träd. Entomol Tidskr 115:81-97 [Indicators of megatree continuity - Swedish distribution of click beetles (Coleoptera, Elateridae) dependent on hollow trees. In Swedish, English abstract]

Ovaskainen O (2004) Habitat-specific movement parameters estimated using mark-recapture data and a diffusion model. Ecology 85:242-257

Peltonen A, Hanski I (1991) Patterns of island occupancy explained by colonization and extinction rates in shrews. Ecology 72:1698-1708

Pulliam HR (1988) Sources, sinks, and population regulation. Am Nat 132:652-661

Ranius T (2000) Minimum viable metapopulation size of a beetle, Osmoderma eremita, living in tree hollows. Anim Conserv 3:37-43

Ranius T (2001) Constancy and asynchrony of Osmoderma eremita populations in tree hollows. Oecologia 126:208-215

Ranius T (2002a) Influence of stand size and quality of tree hollows on saproxylic beetles in Sweden. Biol Conserv 103:85-91

Ranius T (2002b) Population ecology and conservation of beetles and pseudoscorpions living in hollow oaks in Sweden. Animal Biodiversity and Conservation 25.1:53-68

Ranius T, Douwes P (2002) Genetic structure of two pseudoscorpion species living in tree hollows in Sweden. Animal Biodiversity and Conservation 25.2:67-75 
Ranius T, Hedin J (2001) The dispersal rate of a beetle, Osmoderma eremita, living in tree hollows. Oecologia 126:363-370

Ranius T, Jansson N (2002) A comparison of three nethods to survey saproxylic beetles in hollow oaks. Biodiver Conserv 11:1759-1771

Ranius T, Kindvall O (2006) Extinction risk of wood-living model species in forest landscapes as related to forest history and conservation strategy. Land Ecol, in press Ranius T, Wilander P (2000) Occurrence of Larca lata H.J. Hansen (Pseudoscorpionida: Garypidae) and Allechernes wideri C.L. Koch (Pseudoscorpionida: Chernetidae) in tree hollows in relation to habitat quality and density. J Insect Conserv 4:23-31

Roff DA (1994) Habitat persistence and the evolution of wing dimorphism in insects. Am Nat $144: 772-798$

Roslin T (2000) Dung beetle movements at two spatial scales. Oikos 91:323-335

Rukke BA, Midtgaard F (1998) The importance of scale and spatial variables for the fungivorous beetle Boltiphagus reticulatus (Coleoptera, Tenebrionidae) in a fragmented forest landscape. Ecography 21:561-572

Schneider C (2003) The influence of spatial scale on quantifying insect dispersal: an analysis of butterfly data. Ecol Entomol 28:252-256

Siitonen J (2001) Forest management, coarse woody debris and saproxylic organisms: Fennoscandian boreal forests as an example. Ecol Bull 49:11-41

Slatkin M (1987) Gene flow and the geographic structure of natural populations. Science 236:787-792

Southwood TRE (1962) Migration of terrestrial arthropods in relation to habitat. Biol Rev Camb Philos Soc 37:171-214

Speight MCD (1989) Saproxylic invertebrates and their conservation. Council of Europe, Strasbourg 
Sprecher-Uebersax E, Durrer H (2001) Verhaltensstudien beim Hirschkäfer mittels

Telemetrie und Videoaufzeichnungen (Coleoptera, Lucanus cervus L.). Mitteilungen der Naturforschenden Gesellschaften beider Basel 5:161-182

Starzomski BM, Bondrup-Nielsen S (2002) Analysis of movement and the consequence for metapopulation structure of the forked fungus beetle, Bolitotherus cornutus Panzer (Tenebrionidae). Écoscience 9:20-27

Sverdrup-Thygeson A, Midtgaard F (1998) Fungus-infected trees as islands in boreal forest: spatial distribution of the fungivorous beetle Bolitophagus reticulatus (Coleoptera, Tenebrionidae). Écoscience 5:486-493

Thomas CD (2000) Dispersal and extinction in fragmented landscapes. Proc R Soc Lond B 267:139-145

Thomas CD, Thomas JA, Warren MS (1992) Distributions of occupied and vacant butterfly habitats in fragmented landscapes. Oecologia 92:563-567

Togashi K (1990) A field experiment on dispersal of newly emerged adults of Monochamus alternatus (Coleoptera: Cerambycidae). Researches on Population Ecology 32:1-13

Whitlock MC (1992) Nonequilibrium population strucutre in forked fungus beetles: extinction, colonization, and the genetic variance among populations. Am Nat 139:952-970 
Table 1. Beetle species associated with tree hollows, captured in pitfall traps and window traps (Fig. 8) set in the same oak trees $(n=90)$ in south-eastern Sweden. Only species present in $>2.5 \%$ of the traps are included. A) Total number of individuals captured by window traps and pitfall traps. B) Proportion of these individuals that were captured by window traps (from Ranius and Jansson 2002). C) Coefficient and statistical significance ( $* \mathrm{P}<0.05$, *** $\mathrm{P}<0.001$, Kendall's taub) of the relationship between proportion of hollow trees occupied by the species and stand size (from Ranius 2002a).

Species
Elater ferrugineus
Plegaderus caesus
Tenebrio opacus
Osmoderma eremita
Cryptophagus quercinus
Euplectus karsteni
Dendrophilus corticalis
Ampedus cardinalis
Euplectus nanus
Prionychus ater
Ampedus hjorti
Procraerus tibialis
Pseudocistela ceramboides
Allecula morio
Cryptophagus populi
Mycetochara humeralis
Pentaphyllus testaceus

Species

Elater ferrugineus

Plegaderus caesus

Osmoderma eremita

Cryptophagus quercinus

Euplectus karsteni

Dendrophilus corticalis

Euplectus nanus

Prionychus ater

Ampedus hjorti

Pseudocistela ceramboides

Allecula morio

Cryptophagus populi

Pentaphyllus testaceus

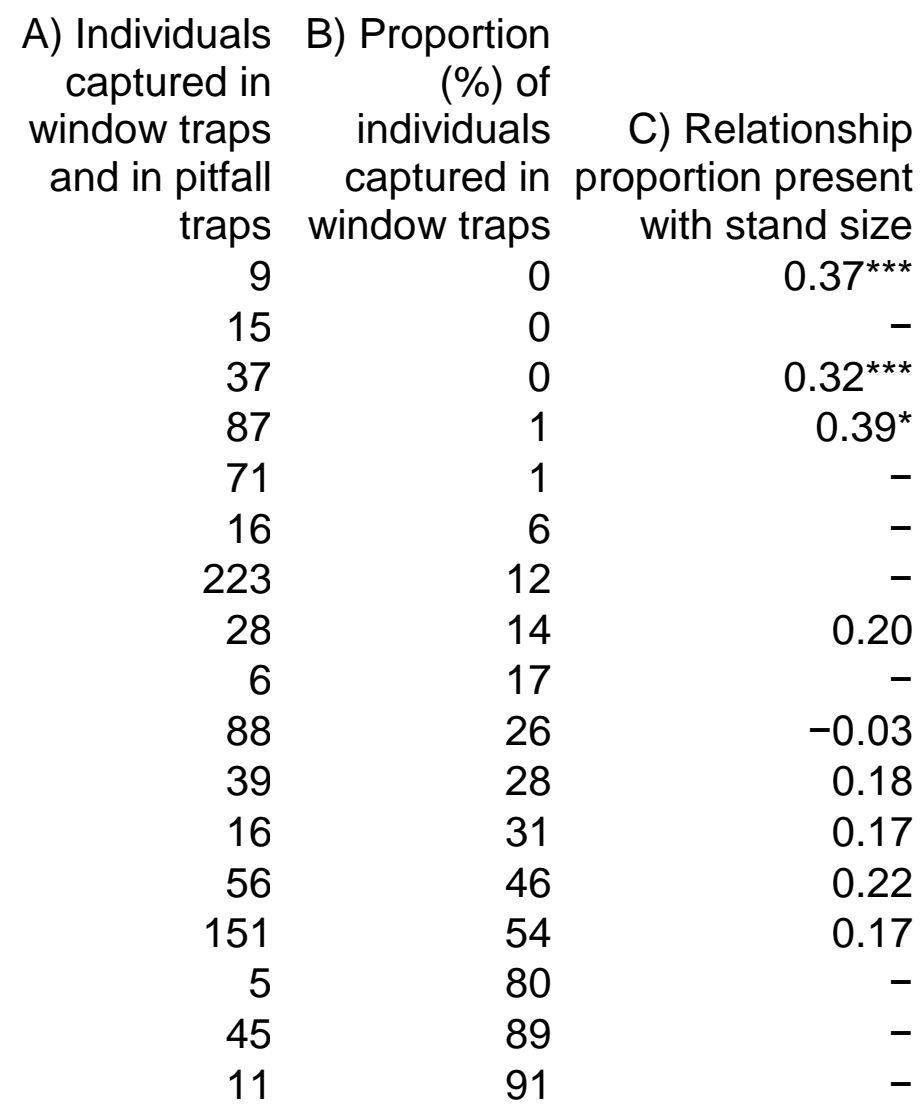


Fig. 1a) In Sweden, Osmoderma eremita and other beetles associated with tree hollows predominantly occur in oak (Quercus robur) pastures grazed by cattle. Photo: Jens Johannesson. b) Pitfall trap set in a trunk hollow, used in a capture-recapture study of $O$. eremita. Photo: Niklas Jönsson.

Fig. 2a) The black tinder fungus beetle Bolitophagus reticulatus is a $5-8 \mathrm{~mm}$ long beetle. b) $B$. reticulatus is associated with sporocarps of the tinder fungus, Fomes fomentarius. Photo: Mats Jonsell.

Fig. 3. Proportion of dispersing $O$. eremita individuals, with dispersal ranges exceeding certain distances. Pooled data from capture-recapture (Ranius and Hedin 2001) and telemetry (Hedin et al. 2003) $(n=21)$ compared with a negative exponential function $(P=\exp (-D / 60)$, where $P$ is probability of a dispersing individual to exceed the distance $D$ (in meters)).

Fig. 4. Osmoderma eremita is a $30 \mathrm{~mm}$ long beetle, here tagged with a radio transmitter. Photo: Jonas Hedin. Reprinted from Hedin and Ranius (2002) with permission from Elsevier.

Fig. 5. Frequency of occurrence / tree in relation to stand size for the beetles Osmoderma eremita, Elater ferrugineus, Tenebrio opacus, and the pseudoscorpion Larca lata (redrawn from Ranius 2002b). Only species with significant relationship with stand size are presented here. Stand size is defined as the number of suitable trees within a cluster with a distance of $<250 \mathrm{~m}$ from one suitable tree to another.

Fig. 6. Principal sketch of a flight mill that has been used to measure the flight ability of insects (from Jonsson 2005). 
Fig. 7. Proportion of beetle individuals flying as far or further than certain distances. Redrawn from a flight-mill study on Bolitophagus reticulatus and Oplocephala haemorrhoidalis by Jonsson (2003).

Fig. 8. Two kinds of traps used to collect beetles in the same hollow trees. Pitfall traps were plastic cups placed in the tree hollows. Window traps consisted of a $30 \times 40 \mathrm{~cm}^{2}$ wide transparent plastic plate with a tray underneath (figure from Ranius 2002b).

Fig. 9. Sporocarp set out to study to what extent it becomes colonised by beetles. The sporocarp has been collected alive and frozen to be sure that no insects are present at the starting point of the experiment. Photo: Mats Jonsell.

Fig. 10. Proportion of sporocarps colonised by A) Cis quadridens and B) Cis glabratus inside (-80 m) and at different distances from the border of an old-growth forest. Redrawn from Jonsson and Nordlander (2006). 
Fig. 1

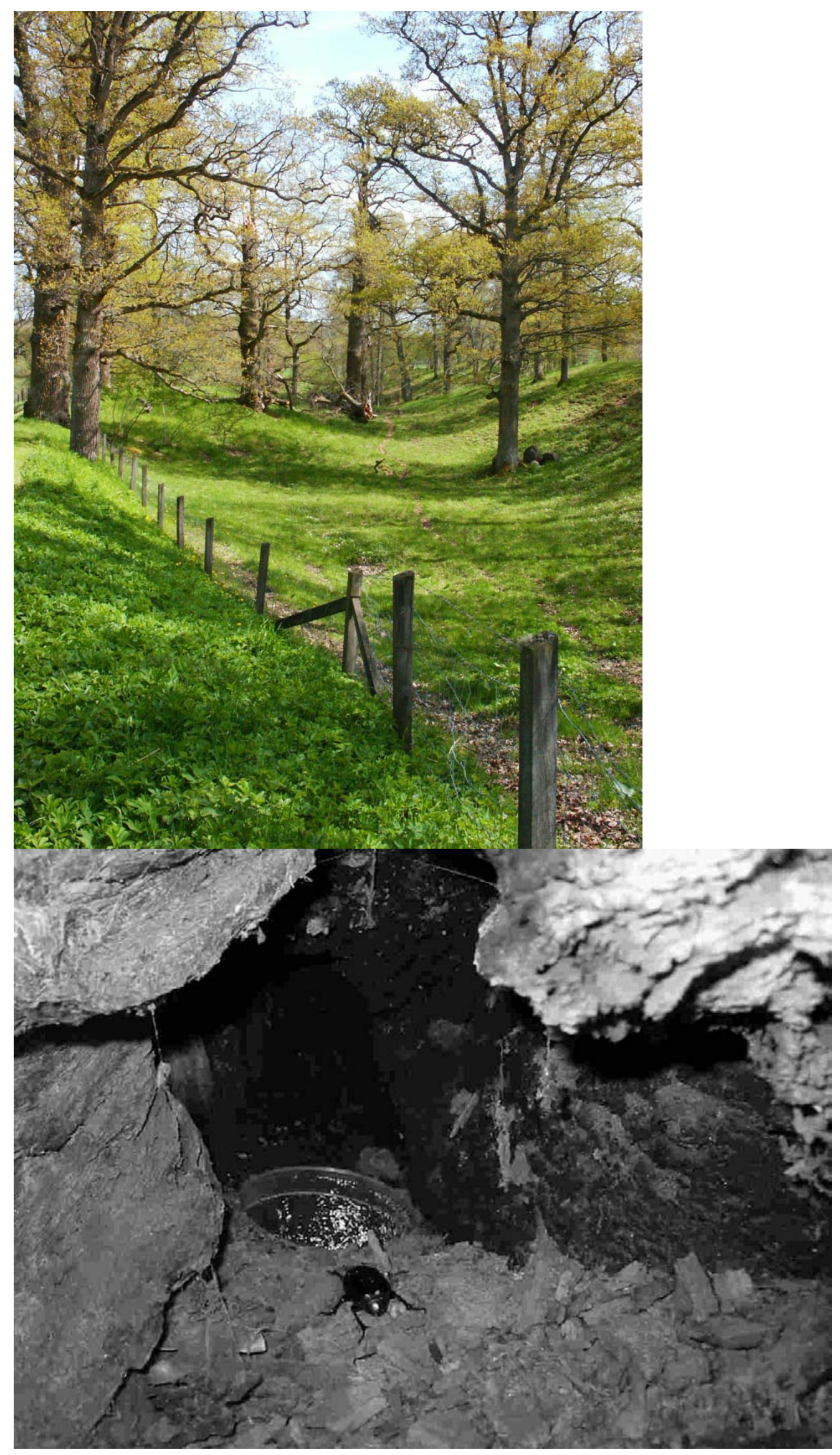


Fig. 2
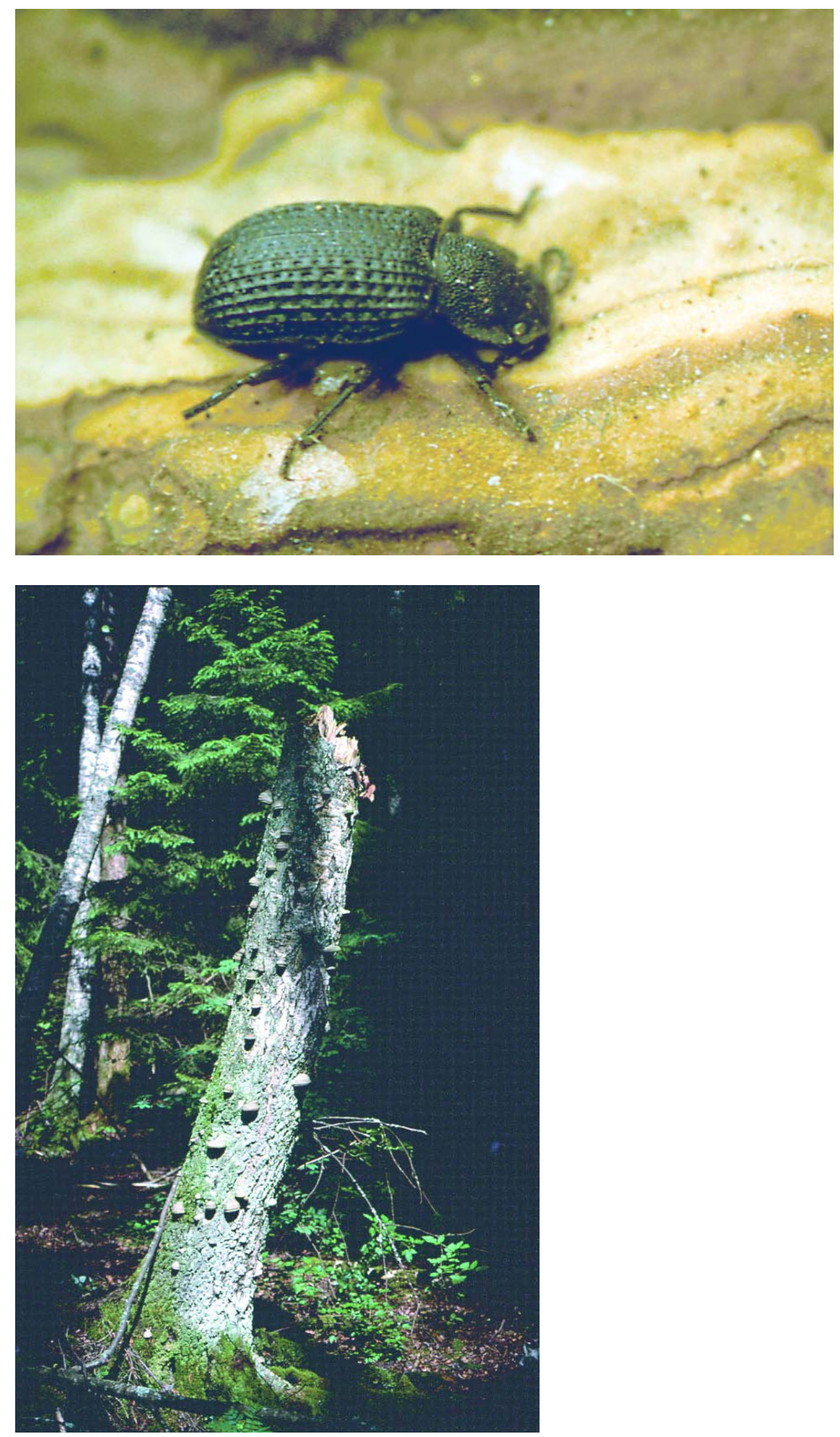
Fig. 3

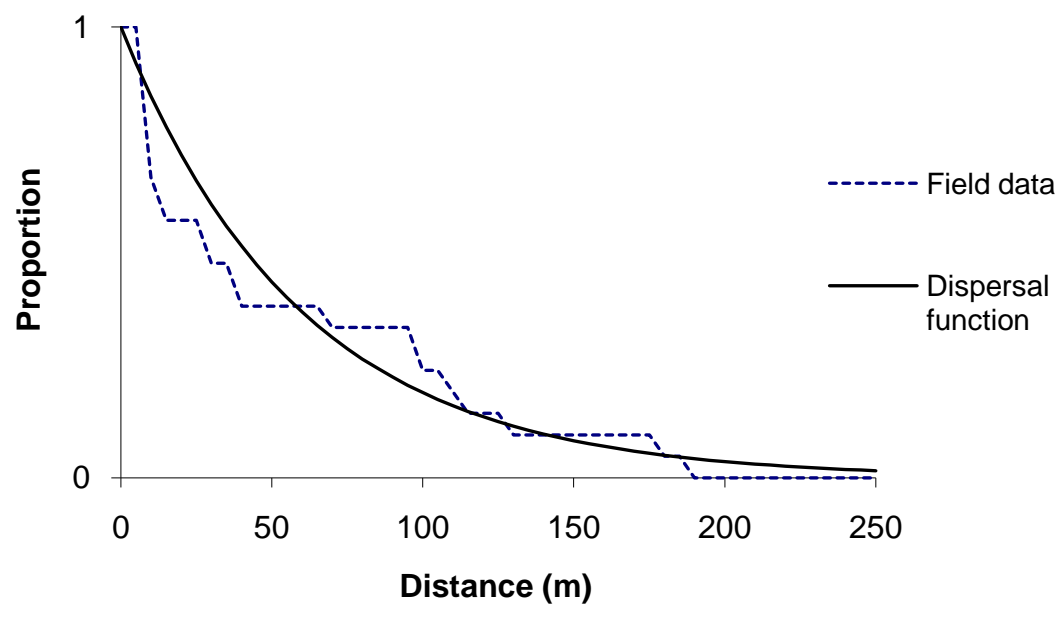


Fig. 4

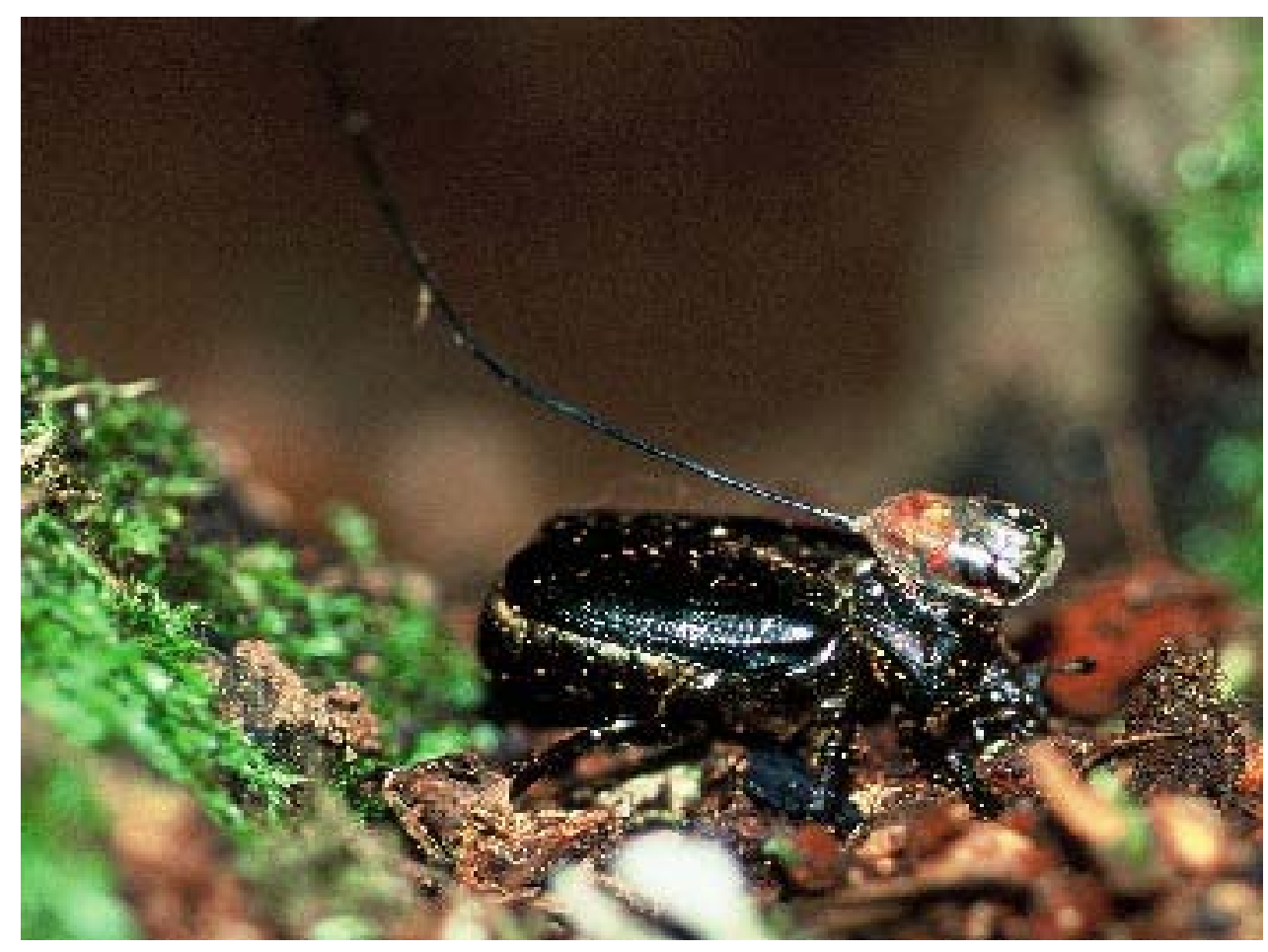


Fig. 5

Osmoderma eremita

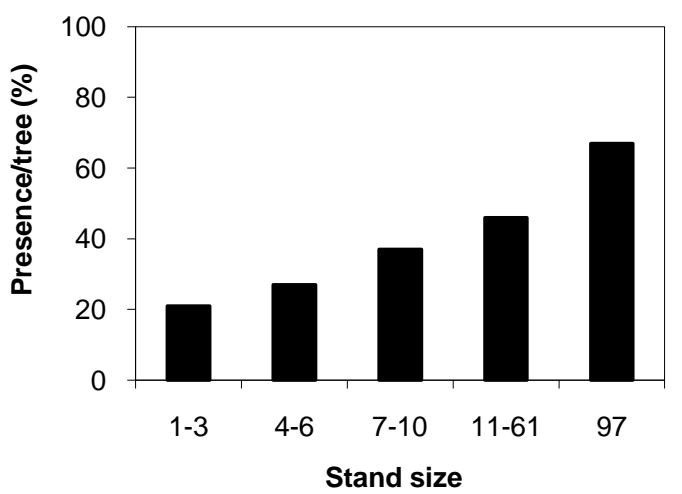

Larca lata

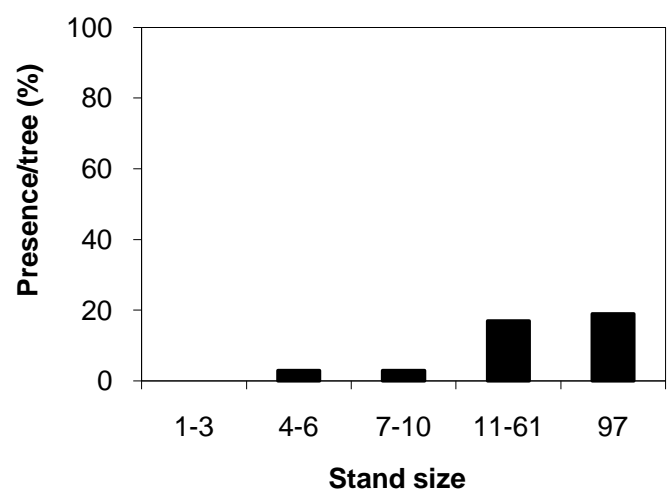

Elater ferrugineus

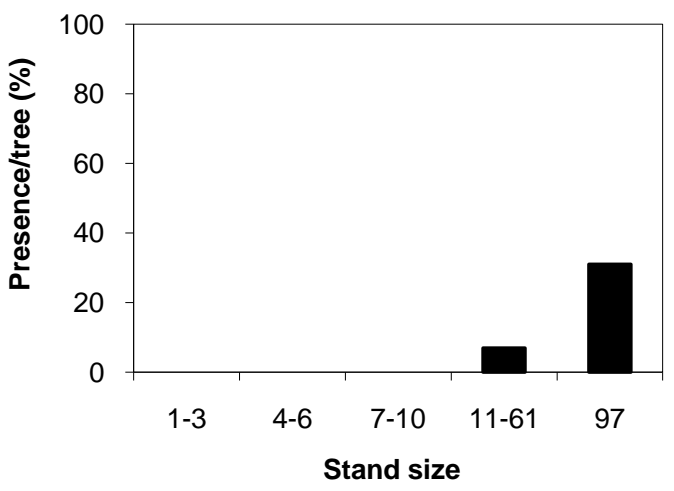

Tenebrio opacus

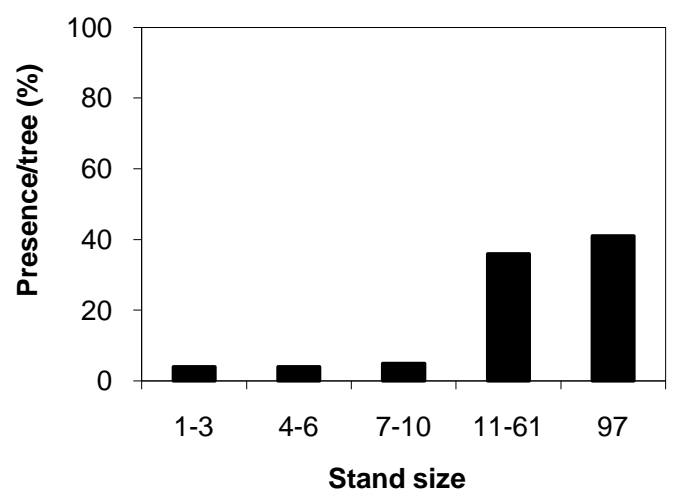


Fig. 6

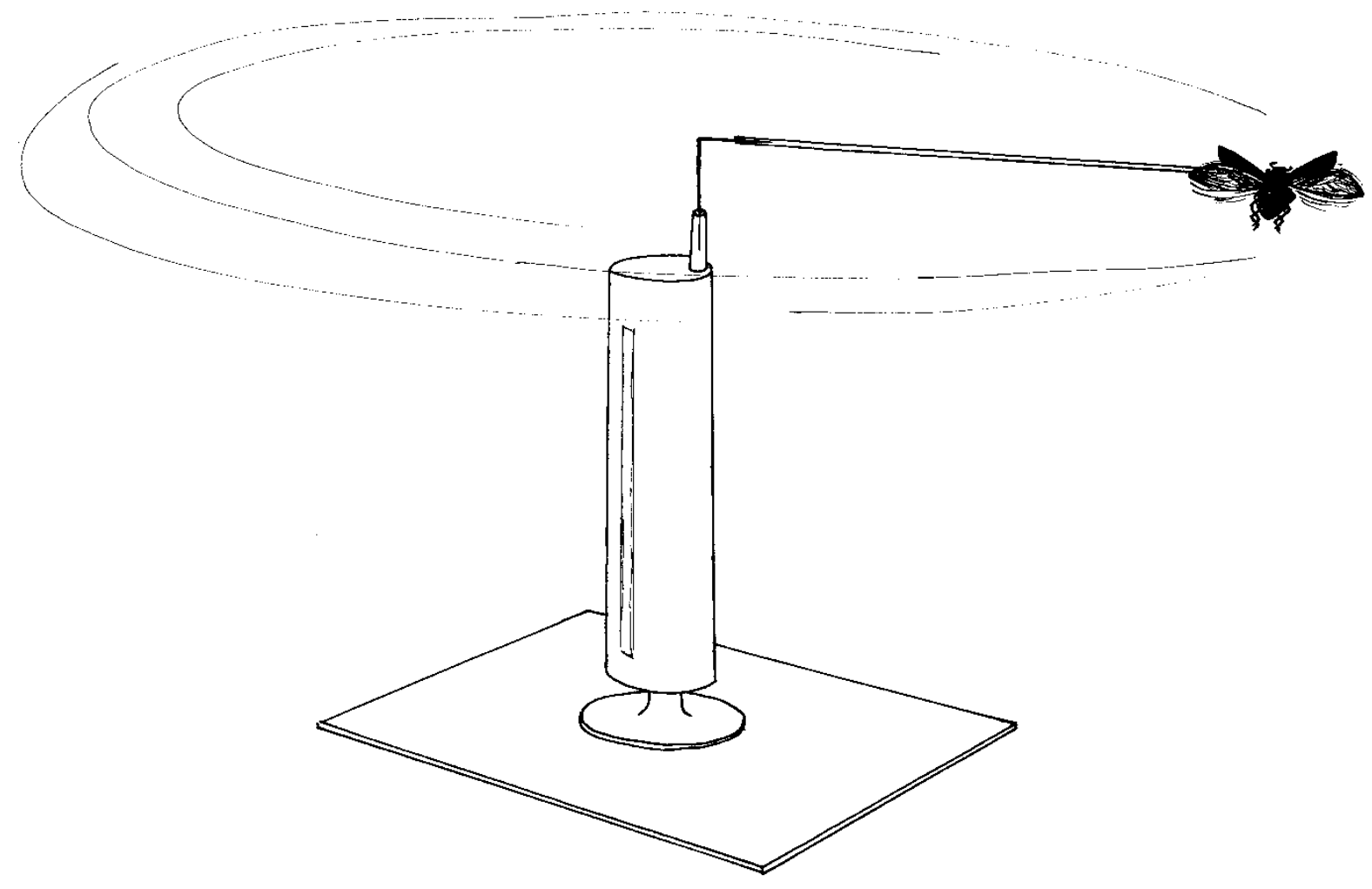

34 
Fig. 7

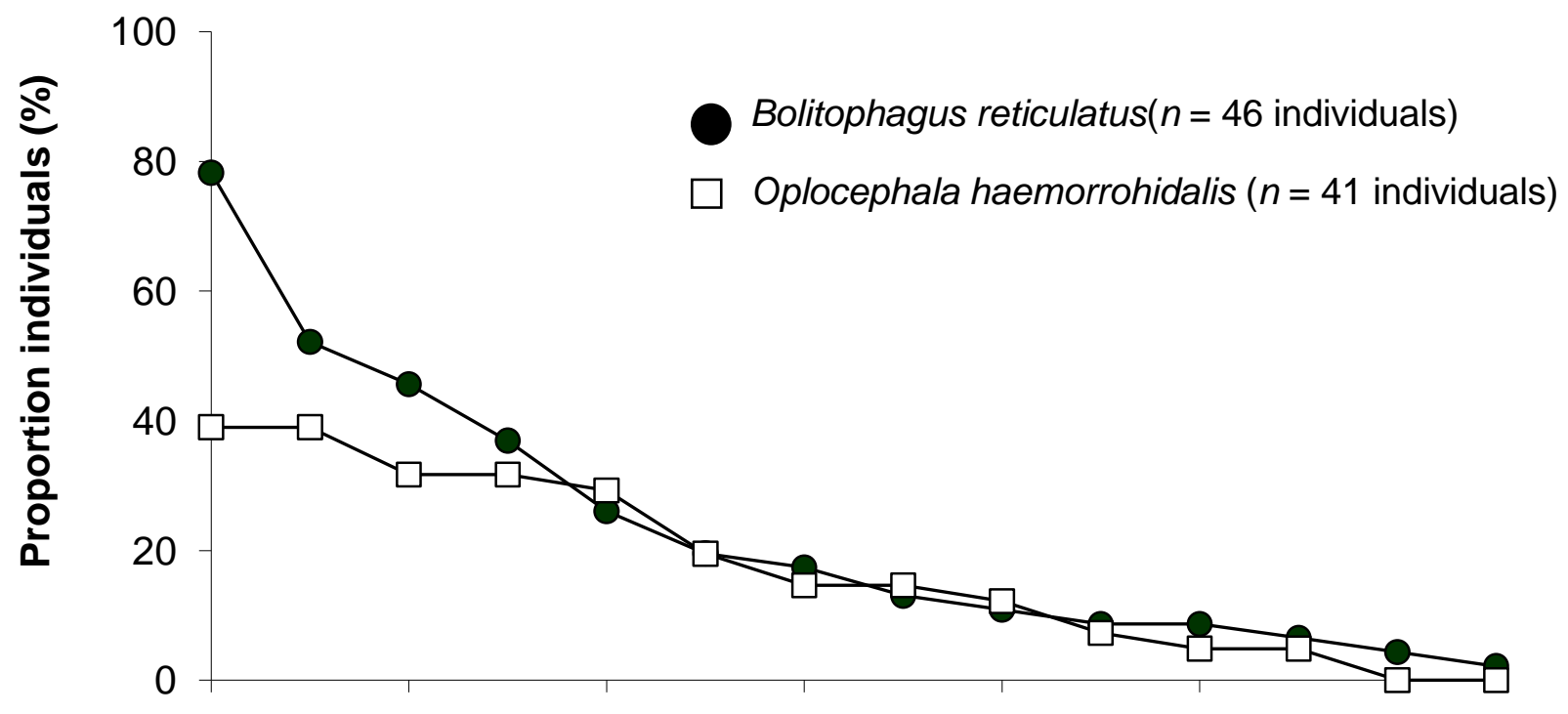

Total flight distance (km) 
Fig. 8

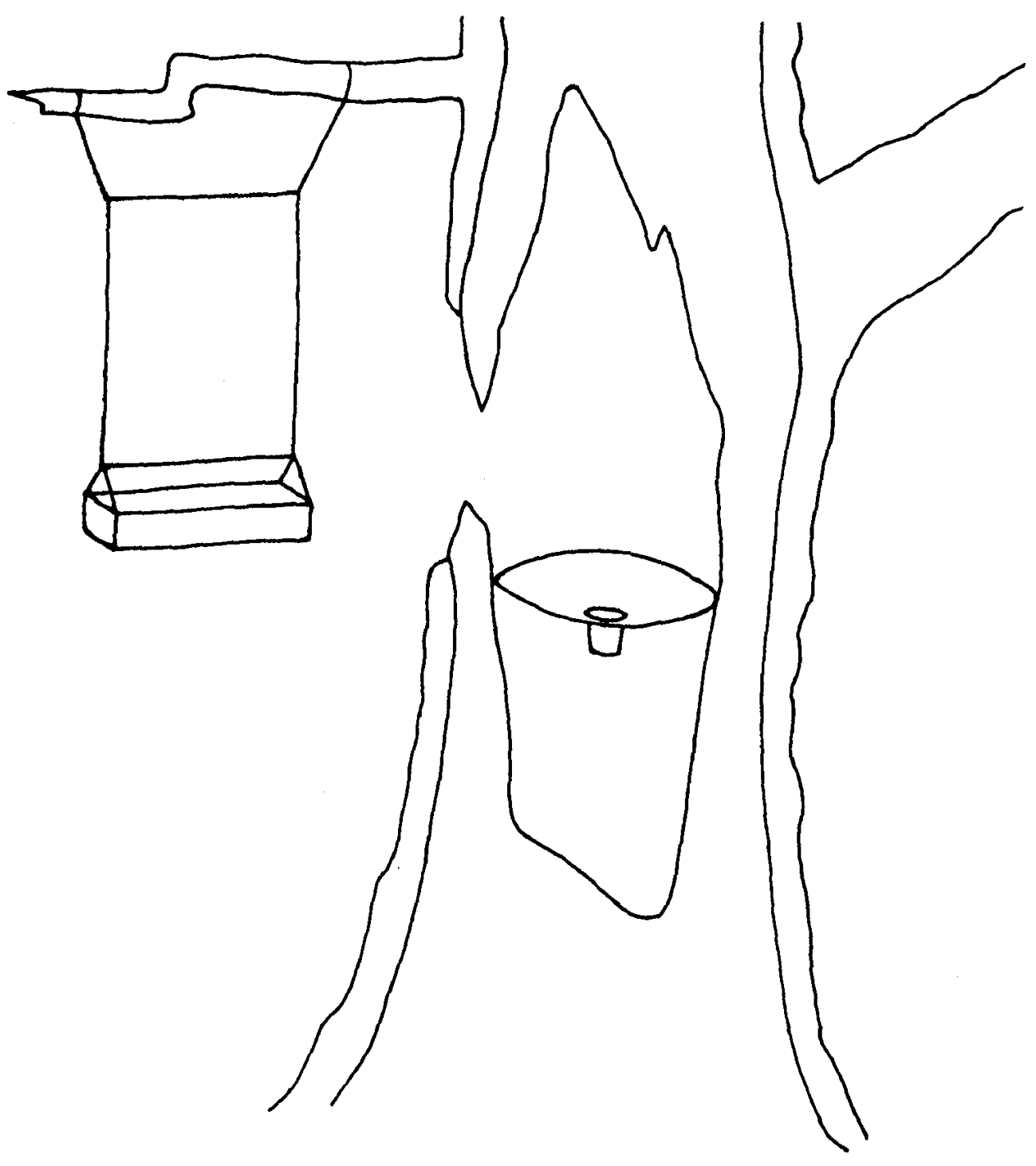


Fig. 9

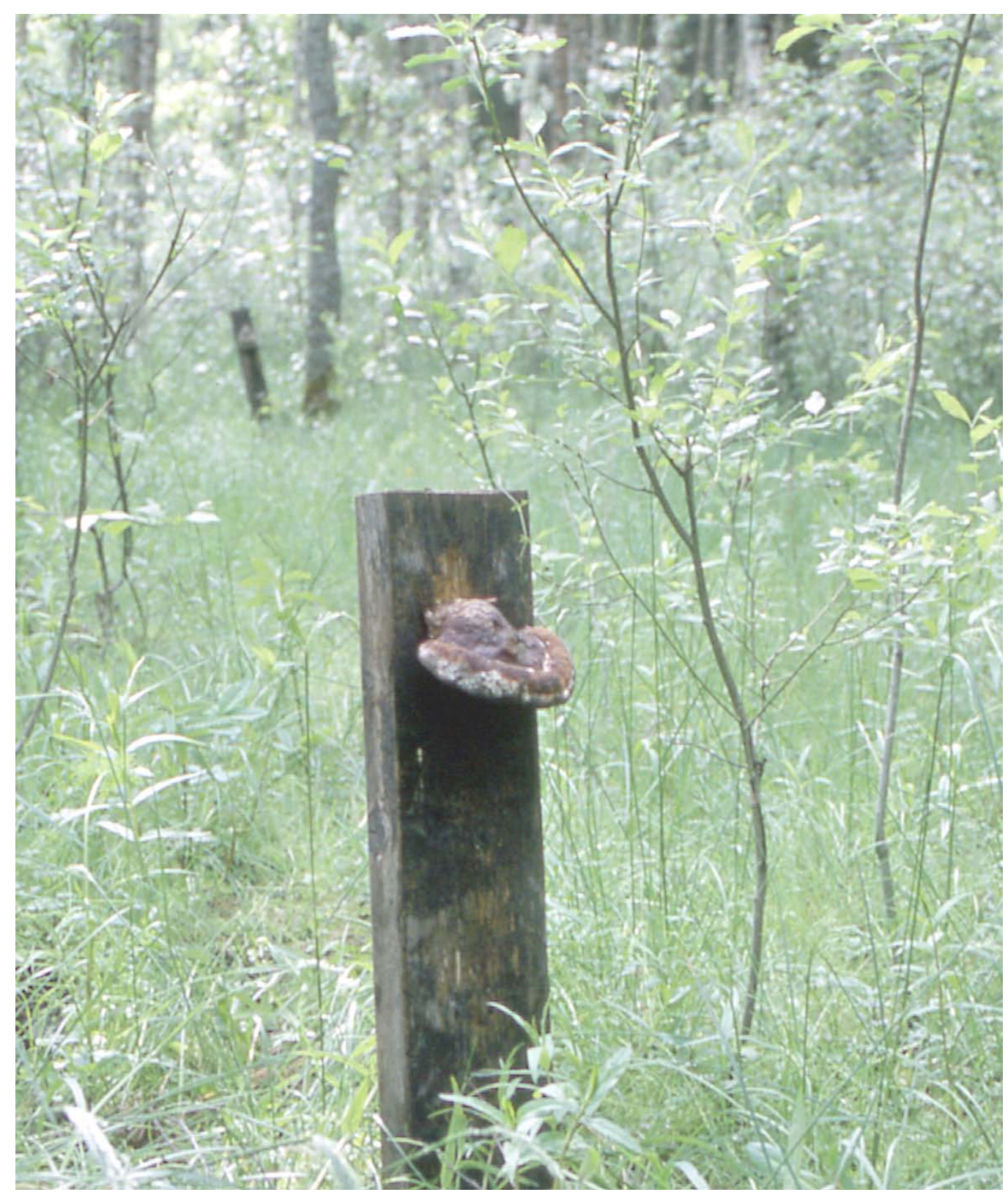


Fig. 10

\section{Cis quadridens}

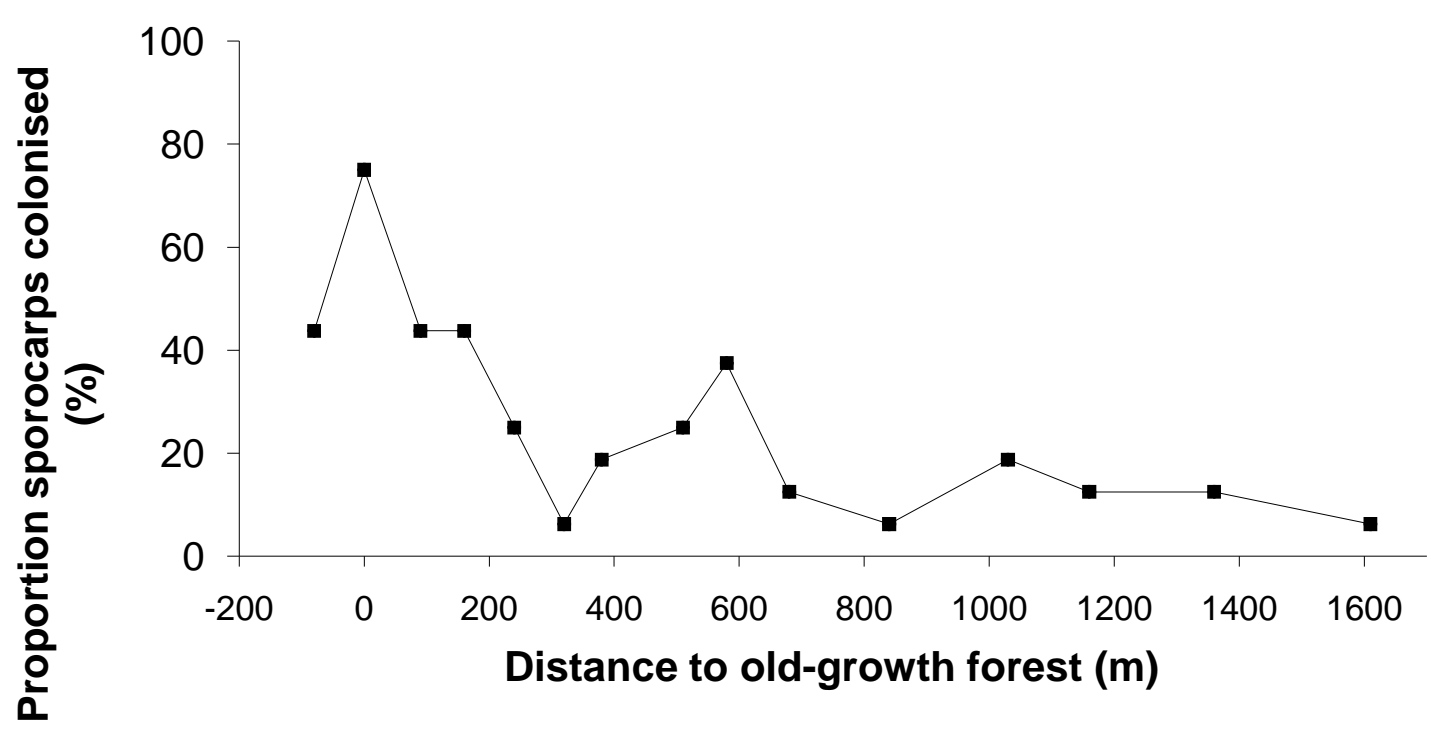

Cis glabratus

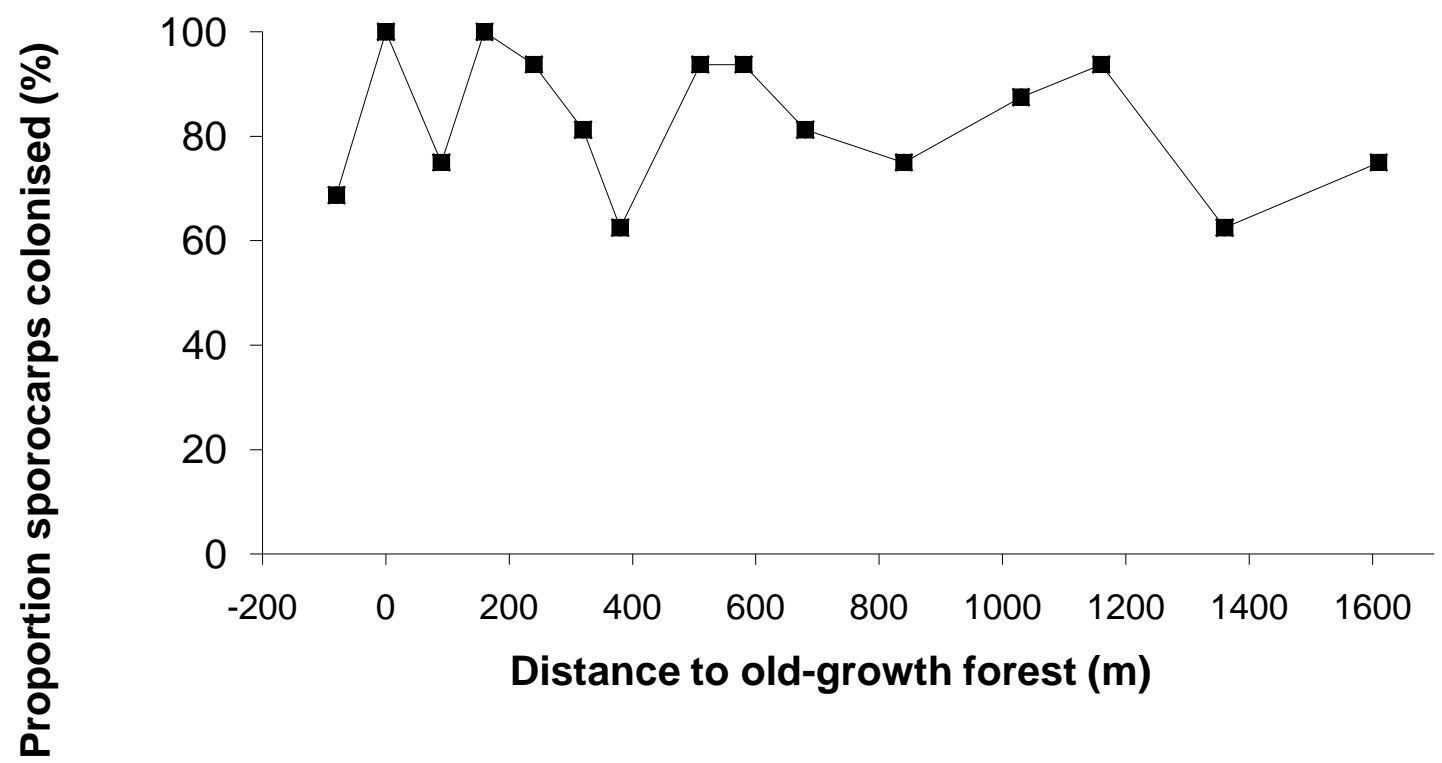

